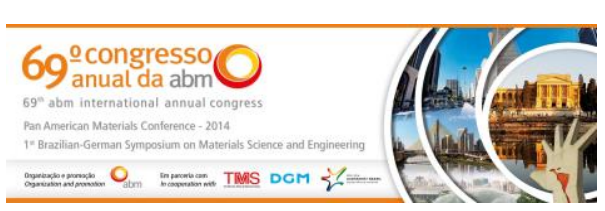

Tema: Estampagem

\title{
EFEITO DE REVESTIMENTOS GALVANIZADOS POR IMERSÃO A QUENTE NO COEFICIENTE DE ATRITO DE UM AÇO BIFÁSICO DESTINADO À INDÚSTRIA AUTOMOTIVA*
}

\author{
Claudeir Carvalho Silveira ${ }^{1}$ \\ Carlos Augusto Silva de Oliveira ${ }^{2}$ \\ Jose Francisco da Silva Filho ${ }^{3}$
}

\section{Resumo}

A necessidade da indústria automobilística de redução de peso, desenvolvimento de designs arrojados e aumento da resistência a corrosão dos automóveis obrigou as indústrias siderúrgicas a produzirem aços galvanizados de alta resistência. Entretanto, para que haja este desenvolvimento é necessário maior conhecimento do comportamento dos revestimentos galvanizados quando submetidos a processos de estampagem. Desgastes da superfície galvanizada, formação de pós, redução da resistência a corrosão e atrito das superfícies são aspectos importantes a considerar no projeto do ferramental de estampagem. Este trabalho teve, portanto, como objetivo a avaliação do efeito dos revestimentos Galvanizing e Galvannealed no coeficiente de atrito de um aço Dual Phase 600. Para avaliação do coeficiente de atrito foi utilizado um tribômetro de ferramenta plana que simula o atrito na estampagem de peças. O trabalho apresenta ainda a caracterização microestrutural do revestimento realizada por microscopia ótica (MO) e eletrônica de varredura (MEV) e espectroscopia de energia dispersiva (EDS). Para avaliação das propriedades do substrato e do revestimento foram utilizadas também medidas de Microdureza. Após a realização dos ensaios, foi caracterizada ainda a evolução dos revestimentos após desgaste promovido pelo tribômetro de ferramenta plana e a identificação e caracterização do fenômeno de stick-slip

Palavras-chave: Aços dual phase; Galvanizing (Gl); Galvannealed (GA); Evolução do revestimento.

\section{EFFECT OF HOT DIP GALVANIZED COATINGS AT COEFFICIENT OF FRICTION OF DUAL PHASE STEEL SUPPLIED FOR THE AUTOMOTIVE INDUSTRY \\ Abstract}

The need of the automotive industry to reduce weight, developing better designs and improve corrosion resistance of the automotive vehicles has forced the steel industry to produce high-strength galvanized steel. However, there is a need for greater knowledge of the behavior of galvanized coatings when subjected to stamping process. Wear of the galvanizing surface, powdering, reduced corrosion resistance and friction of surface, are important subjects to consider in the tools and dies process concept. This study therefore aimed to evaluate the effect of coatings Galvanizing and Galvannealed in the friction coefficient of steel Dual Phase 600. To evaluate the friction coefficients will be used the flat die tribometer that can simulate the friction stamping generally observed in internal and exposed parts. The work also presents the microstructural characterization of the coating performed by optical microscopy techniques, energy dispersive spectroscopy (EDS), scanning electron microscopy (SEM). To evaluate the properties of the substrate and the coating as the initial state were also used microhardness techniques. After finalize the tests, it is expected to characterize the evolution of the coatings and the identification and characterization of the phenomenon of stick-slip.

Keywords: Dual phase steel; Galvanizing (GI); Galvannealed (GA); Evolution of the coating.

1 Eng. Prod. Mecânica, Mestrando em Ciências e Engenharia dos Materiais, Especialista em Engenharia de Produtos, Gerência de Metalurgia, ArcelorMittal Vega, São Francisco do Sul, SC, Brasil.

2 Engenheiro metalúrgico, DSc., professor Associado, Departamento de Engenharia Mecânica, UFSC, Florianópolis, SC, Brasil.

3 Eng.Quimico, M.Sc, Gerência de Área de Laboratório Metalúrgico e de Processos, Gerência de Metalurgia, ArcelorMittal Vega, São Francisco do Sul, SC, Brasil.

\footnotetext{
* Contribuição técnica ao 69 Congresso Anual da ABM - Internacional e ao 14ํㅡㄹ ENEMET - Encontro Nacional de Estudantes de Engenharia Metalúrgica, de Materiais e de Minas, 21 a 25 de julho de 2014, São Paulo, SP, Brasil.
} 


\section{INTRODUÇÃO}

A partir da década de 70 grandes esforços foram realizados para o desenvolvimento de aços galvanizados de alta resistência que propiciassem a redução de peso das carrocerias de automóveis, redução no consumo de combustível e proteção contra corrosão. Assim, diante do aumento necessário da resistência dos aços e do atendimento a design mais arrojados, observaram-se grandes desafios para 0 entendimento do comportamento dos revestimentos utilizados nos processos de estampagem. Atualmente, os principais revestimentos utilizados em aços bifásicos aplicados na indústria automotiva são o Zinco-Puro (Galvanizing-Gl) e Ligas ZincoFerro (Galvannealed-GA). A estampagem dos aços galvanizados de alta resistência podem gerar diferentes problemas, tais como geração de pós nas ferramentas, desgaste da superfície galvanizada e ocasionar recusas das peças finais estampadas. Assim, observa-se que 0 entendimento da microestrutura do revestimento e do comportamento tribológico dos revestimentos são aspectos relevantes a serem considerados no projeto do ferramental e nos processos de otimização da estamparia [1].

A partir da necessidade do uso dos aços galvanizados de alta resistência e da importância do entendimento dos efeitos dos revestimentos na estampagem, o presente trabalho teve como objetivo a avaliação do efeito dos revestimentos zincopuro (Gl) e zinco-ferro (GA) aplicados em um aço Bifásico destinado a indústria automotiva no coeficiente de atrito. Além dos ensaios de atrito, foram utilizados ensaios de microdureza e rugosidade para a caracterização da evolução do desgaste do revestimento diante da atuação do tribômetro de matriz plana. $O$ revestimento foi caracterizado utilizando Microscopia Eletrônica de Varredura com Micro-Análise química EDS.

\subsection{Aços Bifásicos Galvanizados}

Aços Bifásicos Galvanizados são uma classe de aços de alta resistência baixa liga caracterizada por uma microestrutura consistindo de uma matriz ferrítica com aproximadamente 10 a $20 \%$ de martensita. Estes aços têm como características mecânicas a ausência de patamar de escoamento, baixo limite de escoamento a $0,2 \%$, alta taxa de encruamento, alto limite de resistência, alto alongamento uniforme e total, e efeito Bake Hardening. Devido a sua alta taxa de encruamento combinada ao alto alongamento uniforme, estes aços conferem a conformabilidade desejada para aplicações automotivas tais como peças estruturais além de resistência a corrosão [2-3].

As características dos revestimentos dependem da presença e distribuição dos ligas intermetálicas ferro/zinco. $O$ processo de galvanização pode ser entendido pelo diagrama de Zn-Fe proposto por Kubaschewski [4] e Marder [5]

No caso do Gl, observa-se revestimento composto de uma camada intermetálica $\left(\mathrm{Fe}_{2} \mathrm{Al} \mathrm{l}_{5}\right)$ e da fase eta $(\eta)$. Após o pote de zinco, na torre resfriamento ocorre a completa solidificação do revestimento. O GA é produzido a partir da exposição do revestimento zinco puro a um tratamento térmico após o banho de zinco formando microestrutura geralmente composta de fase gama $(\Gamma)$, fase delta $(\delta)$ e fase zeta $(\zeta)$. Dessa forma, o controle dessas fases duras e frágeis torna-se essencial para manutenção da aderência do revestimento e sucesso do processo estampagem dos aços de alta resistência [6].

\footnotetext{
* Contribuição técnica ao 69ำ Congresso Anual da ABM - Internacional e ao 14ํㅡㄹ ENEMET - Encontro Nacional de Estudantes de Engenharia Metalúrgica, de Materiais e de Minas, 21 a 25 de julho de 2014, São Paulo, SP, Brasil.
} 


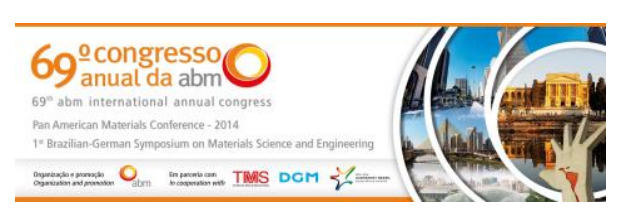

A distribuição das fases intermetálicas e a microestrutura final do GA é uma função do tratamento térmico do revestimento. A partir da modificação da temperatura de tratamento térmico do revestimento é possível obter três tipos característicos de revestimentos com liga de Fe-Zn, são eles: com grande quantidade da fase zeta $(\zeta)$ onde são utilizadas temperaturas menores que $500^{\circ} \mathrm{C}$, com pouquíssimas quantidades de fase zeta $(\zeta)$ produzidas com temperaturas superiores a $500^{\circ} \mathrm{C}$ e revestimentos com quantidades intermediárias de fase zeta $(\zeta)$ e delta $(\delta)$, que podem ser obtidas por uma combinação de fatores de processo de galvanização. $\mathrm{Na}$ Figura 1 é possível verificar evolução microestrutural do Galvannealed a partir de diferentes temperaturas de tratamento térmico do revestimento [7].



(a)

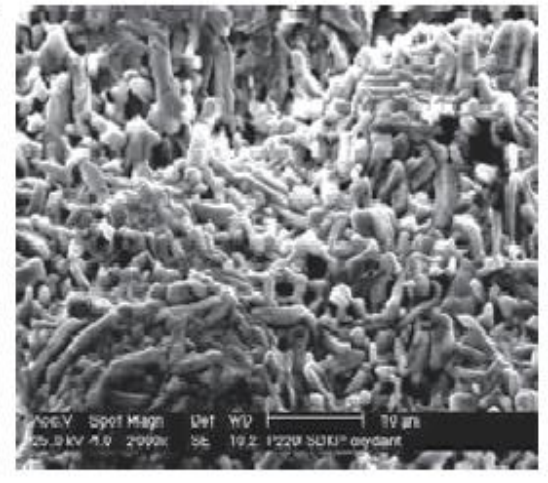

(b)

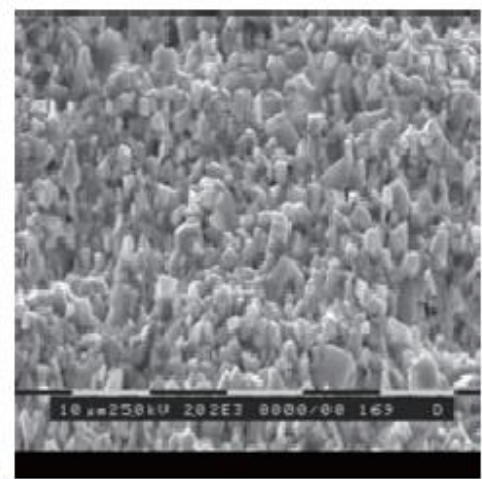

(c)

Figura 1 - Evolução da microestrutural do Galvannealed a partir de diferentes temperaturas de tratamento térmico obtida por MEV: (a) cristais de zeta $(\zeta)$ tipo haste $\left(<500^{\circ} \mathrm{C}\right)$, (b) cristais de tipo haste com arestas menores $(\zeta+\delta)\left(>500^{\circ} \mathrm{C}\right)$ e (c) microestrutura de superfície composta basicamente de fase $\delta$. [7]

No revestimento com grandes quantidades de fase zeta ( $\zeta$ ), observa-se microestrutura característica de cristais em forma de hastes que apresentam nos processos de estampagem boa resistência à formação de pós (Powdering), mas ocorre o aumento do coeficiente de atrito. Nos revestimentos com baixas porcentagens de fase zeta $(\zeta)$, não são observados mais cristais em forma de hastes e sim uma morfologia de pequenos cristais ou sua inexistência.

\subsubsection{Efeito tribologico dos revestimentos na conformabilidade}

Conforme Matuszak [8], do ponto de vista tribológico, os revestimentos galvanizados influenciam diretamente na estampabilidade dos aços alterando o comportamento de fricção das superfícies. Em estudos de avaliação do coeficiente de atrito utilizando ensaios de desgaste com ferramentas planas, verificou-se a existência de diferentes comportamentos do atrito e geração de Powdering em função das fases presentes no revestimento GA. Revestimentos com maiores porcentagens de fase zeta $(\zeta)$ na superfície possuem maiores coeficientes de atrito quando comparados com revestimentos com reduzidas porcentagens. Entretanto, a redução do coeficiente de atrito ocasiona o aumento do teor de ferro no revestimento, o que resulta no aumento da perda de massa e geração de Powdering [9]. A Figura 2 (a) mostra 0 efeito do teor de ferro do revestimento Galvannealed no coeficiente de atrito. Nestes ensaios foi utilizado um tribômetro de ferramenta plana e, (b) a perda de massa (Powdering) obtida através do ensaio de dobramento.

\footnotetext{
* Contribuição técnica ao $69^{\circ}$ Congresso Anual da ABM - Internacional e ao 14ํㅡㄹ ENEMET - Encontro Nacional de Estudantes de Engenharia Metalúrgica, de Materiais e de Minas, 21 a 25 de julho de 2014, São Paulo, SP, Brasil.
} 

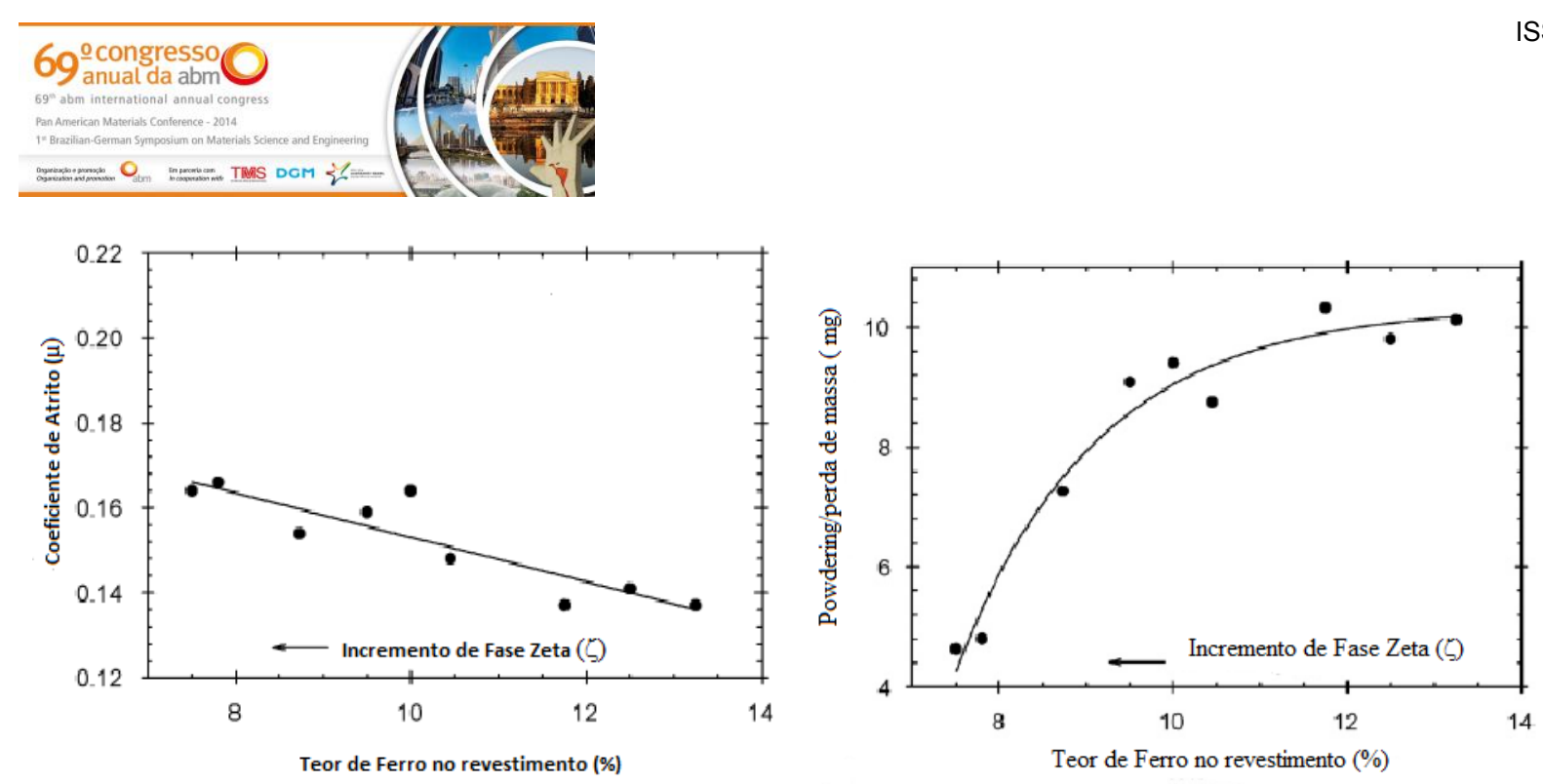

Figura 2-(a) Efeito do teor de ferro do revestimento no coeficiente de atrito e (b) na perda de massa[10]

Diante das características dos revestimentos galvanizados e das condições de estampagem utilizadas para aços de alta resistência, observa-se significante ocorrência de desgaste do revestimento. O fenômeno geralmente utilizado para identificar o início do desgaste é o chamado de stick-slip, que significa a resistência ao deslizamento entre a matriz e a peça estampada, a partir da aplicação de certa pressão de contato, ou força.

\section{MATERIAIS E MÉTODOS}

Os aços Bifásicos Gl e GA estudados, foram produzidos pela ArcelorMittal Vega com composição química contendo teores de carbono $(0,08-0,20 \%)$, manganês $(1,50$ $2,00 \%)$, cromo $(0,20-0,50 \%)$ e Si (Max 0,40\%). Outros elementos tais como molibdênio, titânio e boro também foram observados. O processo de laminação a frio foi realizado objetivando reduções entre 65 e $68 \%$ visando uma espessura final de produto acabado de $1,50 \mathrm{~mm}$ para a bobina sem recozimento (Full Hard). Na linha de galvanização os materiais foram processados obtendo gramaturas de revestimento de zinco entre 50 a $60 \mathrm{~g} / \mathrm{m}^{2}$. A Tabela 1 mostra os resultados de propriedades mecânicas do material utilizado no experimento.

Estes aços serão referidos daqui em diante como DPGI e DPGA, respectivamente.

Tabela 1 - Resultados de propriedades mecânicas dos aços DPGI e DPGA.

\begin{tabular}{c|c|c|c|c|c|c}
\hline Amostra & $\begin{array}{c}\text { Direção do } \\
\text { Ensaio }\end{array}$ & LE (MPa) & $\begin{array}{c}\text { LR } \\
(\mathrm{MPa})\end{array}$ & $\begin{array}{c}\mathrm{Al}(80) \\
\%\end{array}$ & Valor "r" & Valor "n" \\
\hline DPGI & Longitudinal & 382 & 653 & 26 & 0,89 & 0,184 \\
\hline DPGA & Longitudinal & 392 & 626 & 26 & 0,84 & 0,147 \\
\hline \multicolumn{2}{l}{ Norma ASTM A1079-12 } & $>340$ & $>590$ & $>21$ & - & $>0,14$ \\
\hline
\end{tabular}

Fonte: ArcelorMittal Vega 2013

\subsection{Microestrutural e Tribologica}

A avaliação da microestrutura do aço base para identificar as fases presentes foi realizada em Microscópio Eletrônico de Varredura (JEOL de Modelo JSM 6360). As amostras foram cortadas no sentido de laminação, embutidas, lixadas utilizando lixa de granulometria 120, 320, 800 e 1200 $\mu \mathrm{m}$ e polidas com pasta de diamante tipo JP4 (3-6 Micra) e JP1/4 (0-1/2 Micra). Posteriormente, estas amostras foram atacadas

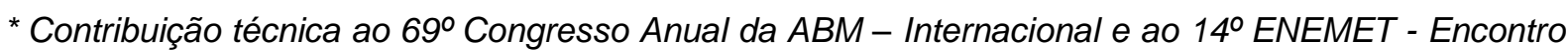
Nacional de Estudantes de Engenharia Metalúrgica, de Materiais e de Minas, 21 a 25 de julho de 2014, São Paulo, SP, Brasil.
} 
com solução de lepera (Picral + Metabisulfito de Sódio) para revelar as fases presentes e os contornos de grão.

O revestimento foi avaliado com relação à formação da camada intermetálica, composição química e microestrutura. Para caracterização das amostras foram utilizados os mesmos procedimentos indicados acima para o aço base. A avaliação da microestrutura e composição química dos revestimentos foi realizada utilizando Microscópio Eletrônico de Varredura (JEOL, Modelo JSM 6360) com Micro-Análise Química (EDS). Foram obtidas imagens referentes às microestruturas de superfície e seção transversal do revestimento.

A caracterização do revestimento através de microdureza foi utilizada em dois momentos. Uma primeira para avaliar o material como recebido, e em segundo momento para avaliar a evolução do revestimento após ensaio tribológico. Para avaliação do material como recebido, a microdureza do revestimento foi realizada utilizado um microdurômetro Vickers, marca SHIMADZU (mod. HMV), com carga de 2,94N por um tempo mínimo igual à 10 segundos e indentador de base piramidal. As medições foram realizadas nos materiais DPGI, DPGA considerando áreas de baixo (BR) e alto relevo (AR) identificadas visualmente através de microscópio eletrônico de varredura. Áreas de alto relevo foram consideradas como áreas visivelmente submetidas ao laminador de encruamento da linha de galvanização. O principal objetivo foi verificar a influência do laminador de encruamento na Microdureza destas áreas (alto e baixo relevo). O ensaio foi realizado seguindo a norma (ASTM A370-12a). Cada valor apresentado é o resultado da média entre cinco endentações. A Figura 3 mostra as regiões da superfície onde foram realizadas as medições de Microdureza.

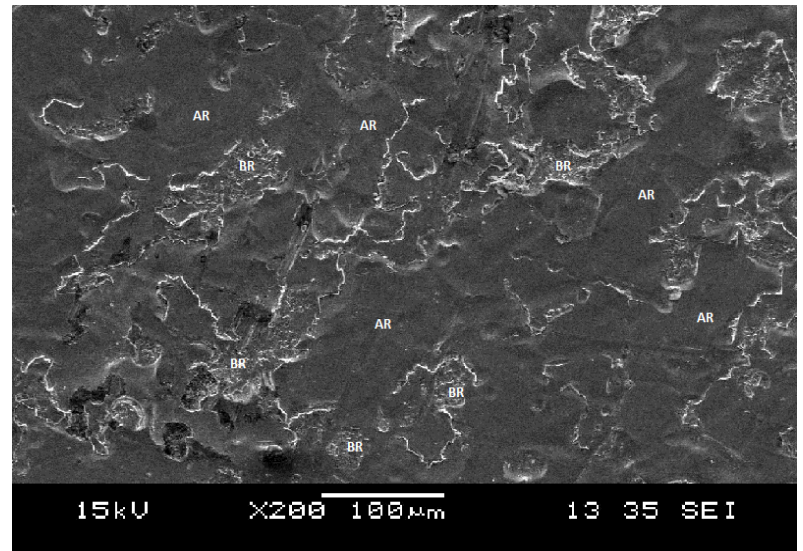

(a)

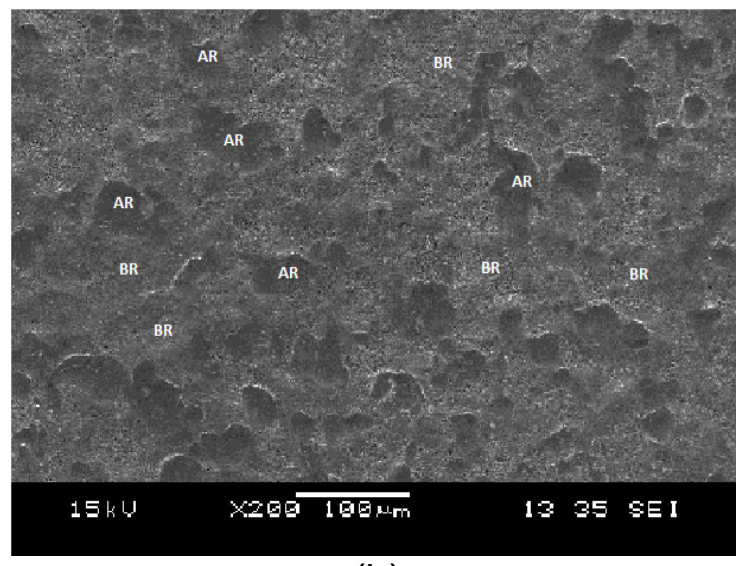

(b)

Figura 3- Identificação das áreas de baixo (BR) e alto relevo (AR) avaliadas na medição de Microdureza (HV).

\subsection{Caracterização Tribologica}

O coeficiente de atrito cinético para os dois revestimentos foi determinado utilizando tribômetro de marca QUIRI com célula de carga de 10.000 N, curso máximo de 150 $\mathrm{mm}$. Foi utilizada matriz plana de carboneto de tungstênio de área de contado de $100 \mathrm{~mm}^{2}(10 \times 10 \mathrm{~mm})$. Inicialmente os corpos de prova de $35 \mathrm{~mm}$ (cortados no sentido transversal ao de laminação) por $400 \mathrm{~mm}$ e as ferramentas de fricção do tribômetro foram limpas por ultrason e solução de solvente Haku 1025 ASR e spray de éter de petróleo. O procedimento consistiu em tracionar uma das extremidades da chapa enquanto blocos idênticos são simetricamente postos nas duas faces da

\footnotetext{
* Contribuição técnica ao $69^{\circ}$ Congresso Anual da ABM - Internacional e ao 14ํㅡㄹ ENEMET - Encontro Nacional de Estudantes de Engenharia Metalúrgica, de Materiais e de Minas, 21 a 25 de julho de 2014, São Paulo, SP, Brasil.
} 


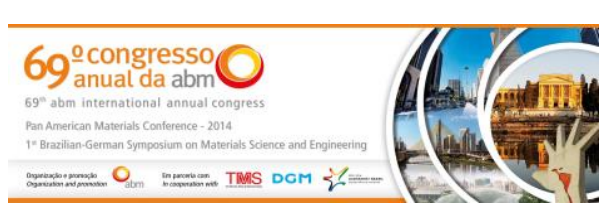

chapa. Um bloco é fixo enquanto o outro possui força controlada. Os corpos de prova foram oleados com óleo de estampagem de marca Quaker 6130 e submetidos a níveis de aperto crescentes de 0,30 a $80 \mathrm{MPa}$. $\mathrm{O}$ ensaio foi realizado a velocidade constante de deslizamento de $0,10 \mathrm{~m} / \mathrm{min}$ e a temperatura ambiente. A Figura 4 mostra esquematicamente o ensaio de coeficiente de fricção realizado.

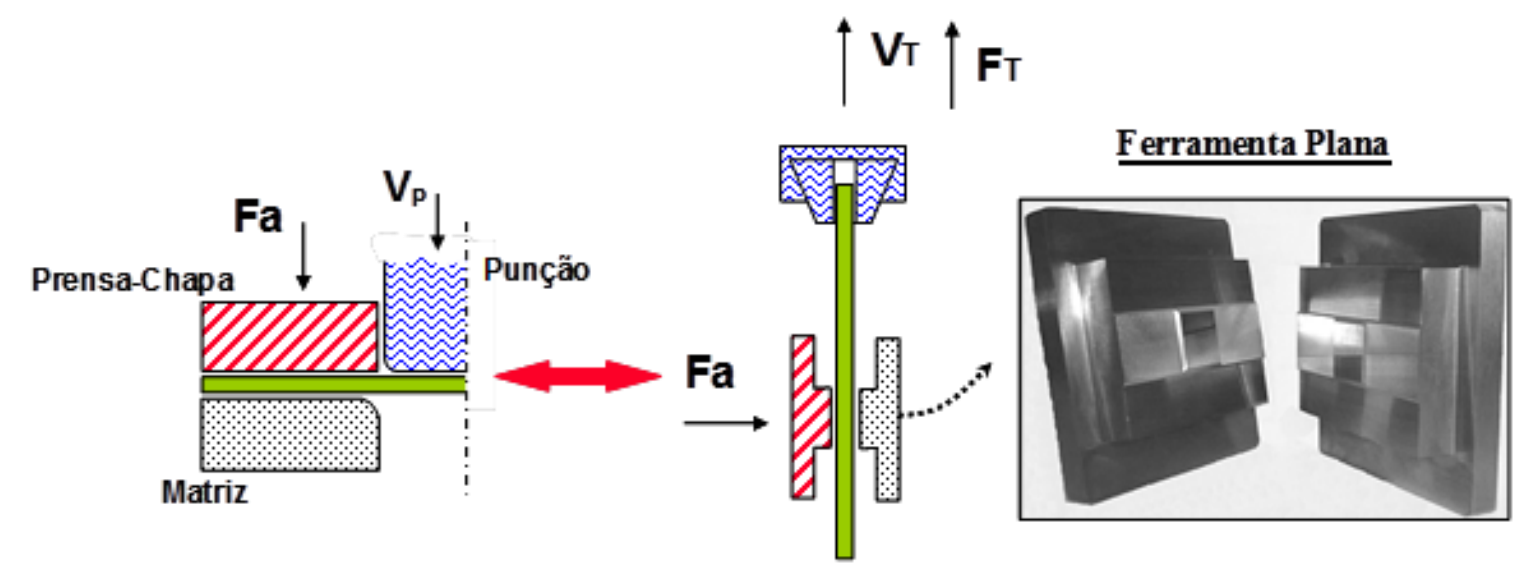

Fonte : ArcelorMittal Maizières (2013)

Figura 4 - Esquema de realização do ensaio de Coeficiente de fricção.

O Coeficiente de Atrito Cinético, $\mu$, foi definido a partir da obtenção das medidas das forças de aperto (Fa) e tração (Ft). O cálculo foi realizado como indicado abaixo:

$$
\mu=\frac{F_{T}}{2 F_{A}}
$$

Onde: FTé a Força de Tração (MPa) e $\mathrm{F}_{\mathrm{A}}$ e a força de aperto (MPa).

\subsection{Caracterizaçao da Evolução do Revestimento}

Objetivando avaliar a evolução do desgaste da superfície galvanizada ao longo do curso percorrido pelo tribômetro, as amostras submetidas à avaliação do coeficiente de fricção foram caracterizadas utilizando microscopia ótica, microdureza, rugosidade e densidade de picos. A amostra foi divida em oito regiões, sendo a região 0 , material como recebido, e sete áreas ao longo da área percorrida pelo tribômetro.

A Figura 5 mostra o esquema dos locais avaliados objetivando a avaliação da evolução microestrutural do revestimento.

Para avaliação da evolução microestrutural da superfície galvanizada foi utilizado Microscópio Ótico (modelo Zeiss-A1m) com software analisador de imagens (modelo Axio Vision). Antes da realização das análises de rugosidade das superfícies, as amostras foram limpas com álcool etílico $95 \mathrm{GL}$. Na medição foi utilizado o Rugosímetro Taylor Hobson, de modelo Talysurf 50, Cut-Off de 2,5mm e norma SEP1940. Para caracterização da evolução da microdureza da superfície do revestimento foi utilizado microdurômetro Vickers de marca SHIMADZU - mod. HMV com carga $0,98 \mathrm{~N}$ (HV-0,01) para o DPGI e DPGA. Foi usado tempo igual à 10 segundos de endentação. $O$ ensaio foi realizado seguindo a norma (ASTM A370-12a). Os valores apresentados são uma média de cinco endentações.

\footnotetext{
* Contribuição técnica ao $69^{\circ}$ Congresso Anual da ABM - Internacional e ao 14ํㅡㄹ ENEMET - Encontro Nacional de Estudantes de Engenharia Metalúrgica, de Materiais e de Minas, 21 a 25 de julho de 2014, São Paulo, SP, Brasil.
} 

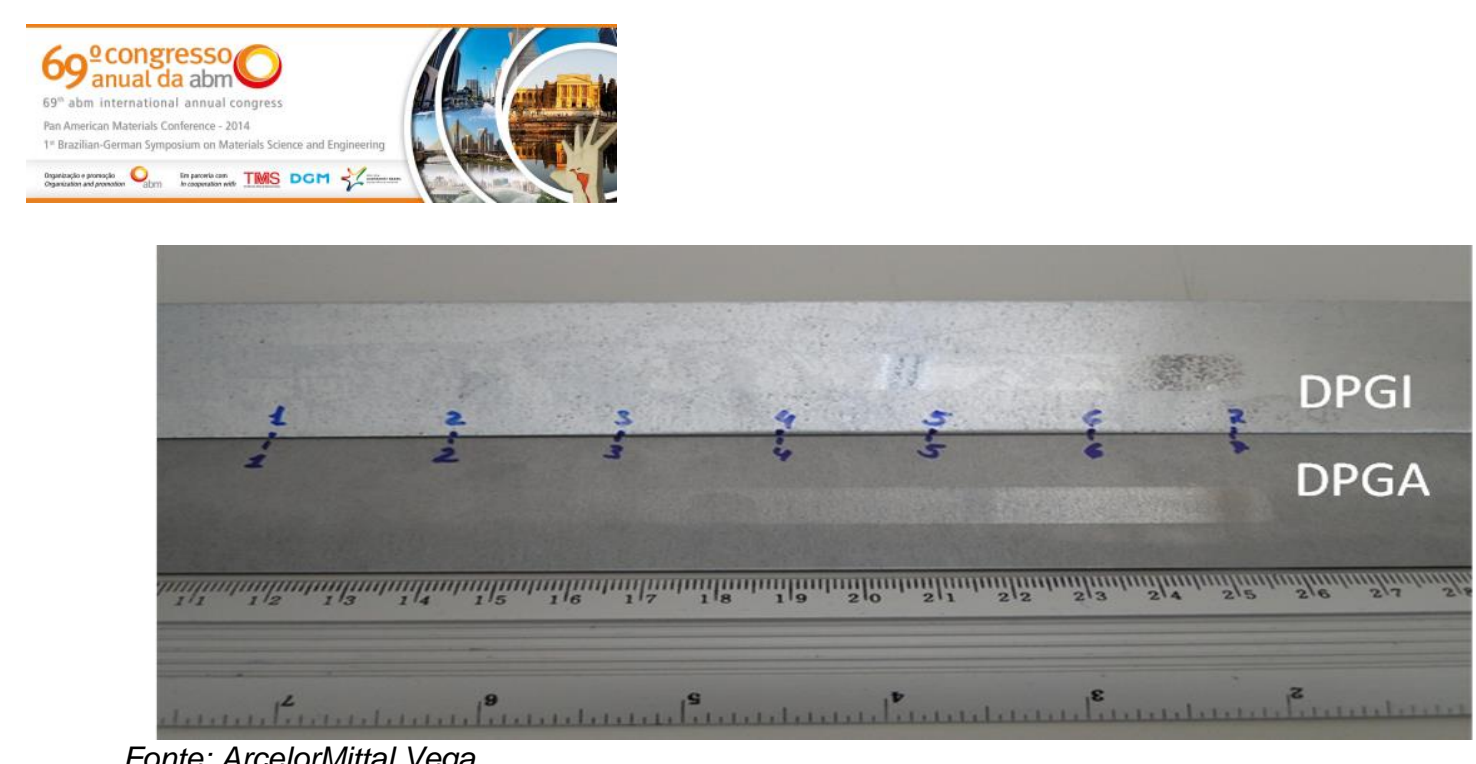

Fonte: ArcelorMittal Vega

Figura 5 - Esquema dos locais de avaliação da evolução Microestrutura do revestimento.

\section{RESULTADOS E DISCUSSÃO}

Nos aços bifásicos Gl e GA a microestrutura ferrita-martensita é obtida através de um recozimento intercrítico seguido de resfriamento até a temperatura de $460^{\circ} \mathrm{C}$ (temperatura do pote de zinco). No caso do DPGA, em particular, ocorre o revenimento da martensita com a utilização do tratamento térmico do revestimento. Com o revenimento da martensita durante o tratamento galvannealing, espera-se pequena redução no limite de resistência do produto final. Na Figura 6 são apresentadas as microestruturas do DPGI e DPGA na condição inicial, obtidas por microscopia eletrônica de varredura. Em ambas as microestruturas é possível verificar a matriz constituída de ferrita (cor cinza) e presença de martensita, em branco.

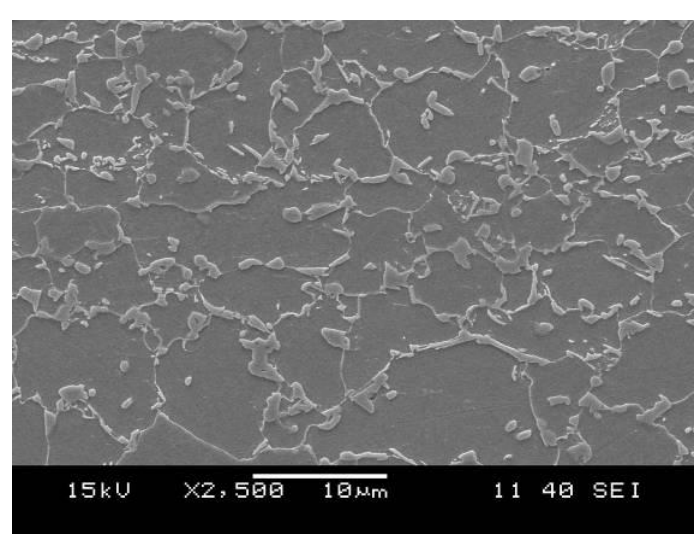

(a)

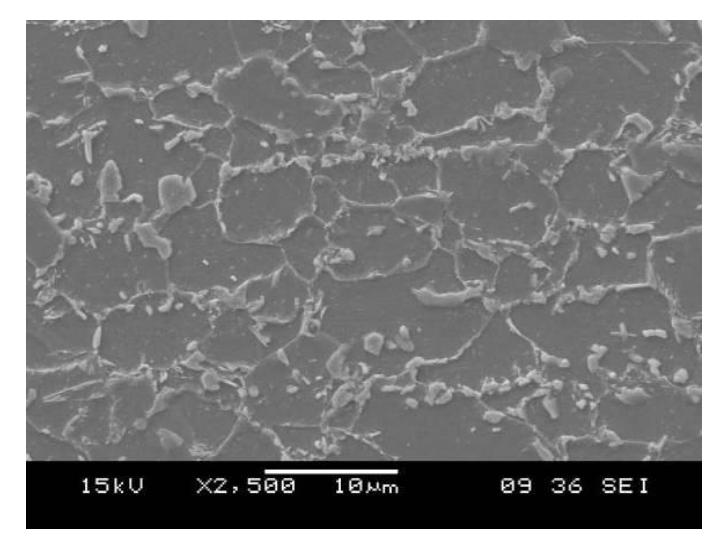

(b)

Fonte: ArcelorMittal Vega 2013

Figura 6 - Microestrutura de superfície (a) DPGI (b) DPGA obtida por microscopia eletrônica de Varredura.

Aspectos relacionados à formação do revestimento metálico influenciam diretamente no coeficiente de atrito do material e no desempenho dos processos de estampagem. Assim a formação da camada intermetálica e do revestimento são importantes para o sucesso do processo de estampagem e da qualidade das peças estampadas [9].

Para o DPGI foi encontrada a espessura média de camada intermetálica de $0,34 \mu \mathrm{m}$ na face superior e 0,35 $\mu \mathrm{m}$ na face inferior. Foi observada ao longo da superfície e da seção do revestimento, composição química de $100 \%$ de zinco, ou seja,

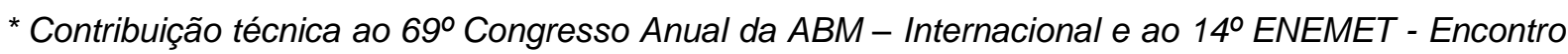
Nacional de Estudantes de Engenharia Metalúrgica, de Materiais e de Minas, 21 a 25 de julho de 2014, São Paulo, SP, Brasil.
} 




predominância da fase eta (ๆ). Também foi observada uma camada intermetálica formada entre o aço base e o revestimento com composição $\mathrm{Fe}_{2} \mathrm{Al}_{5}$.

No caso do DPGA, foi avaliada a espessura da fase Gama $(\Gamma)$ que é a primeira fase que se forma após o aço base. A espessura média da fase Gama $(\Gamma)$ na face superior foi de $0,73 \mu \mathrm{m}$ e de $0,81 \mu \mathrm{m}$ na face inferior. Na seção do DPGA foi verificado teores de alumínio entre 0,38 a $0,72 \%$, quantidades de ferro entre 10 e $11 \%$ e teores de zinco entre 87 e $89 \%$ para os pontos avaliados. No caso da superfície, foram avaliados 8 pontos onde foram verificados teores de alumínio $(0,40-0,70 \%)$, ferro (10-11\%) e Zinco (87-89\%). O revestimento possuía quantidades de fase zeta $(\zeta)$ inferiores a $1,0 \%$. Na Figura 7, são apresentadas para o aço DPGA, as microestruturas de superfície e seção do revestimento, obtidas por Microscopia Eletrônica de Varredura (MEV).

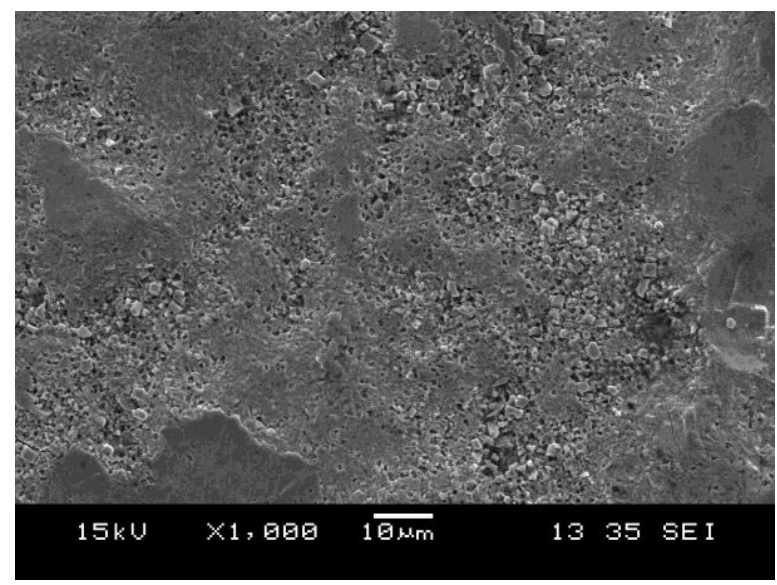

(a)

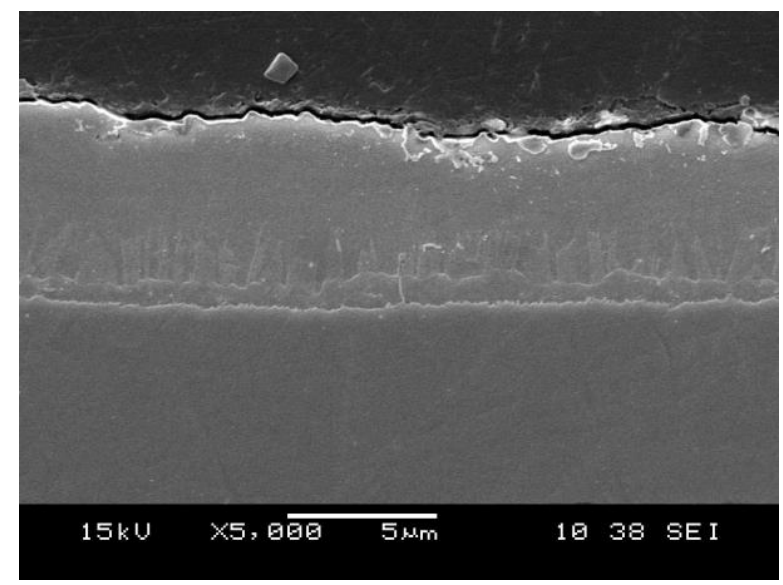

(b)

Fonte: ArcelorMittal Vega 2013

Figura 7 - Microestruturas da superfície (a) e (b) e seção dos materiais DPGA obtida por Microscopia Eletrônica de Varredura (MEV).

Objetivando avaliar a influência do laminador de encruamento nos revestimentos GI e GA aplicados no aço bifásico, foi utilizada técnica de microdureza. A técnica foi aplicada em áreas de alto (AR) e baixo relevo (BR) em amostras de estado como recebido. A Figura 8 mostra os resultados de microdureza para os DPGI e DPGA das superfícies. Para o DPGI, de composição química de aproximadamente $99 \%$ de zinco e composta basicamente de fase eta $(\eta)$ não ocorreu diferenças significativas de microdureza entre as áreas de baixo e alto relevo. No caso do DPGA observouse comportamento diferente com relação ao DPGI. Ocorreu elevada diferença de microdureza entre as áreas de baixa $(B R)$ e alto relevo (AR). Este aumento significativo da microdureza superficial do revestimento é devido a utilização do laminador de encruamento que para o DPGA, além de proporcionar o nivelamento da superfície do revestimento provoca maior encruamento localizado. Isso não é verificado no DPGI devido a ductilidade da fase eta ( ) composta de zinco puro.

\footnotetext{
* Contribuição técnica ao $69^{\circ}$ Congresso Anual da ABM - Internacional e ao 14ํㅡㄹ ENEMET - Encontro Nacional de Estudantes de Engenharia Metalúrgica, de Materiais e de Minas, 21 a 25 de julho de 2014, São Paulo, SP, Brasil.
} 

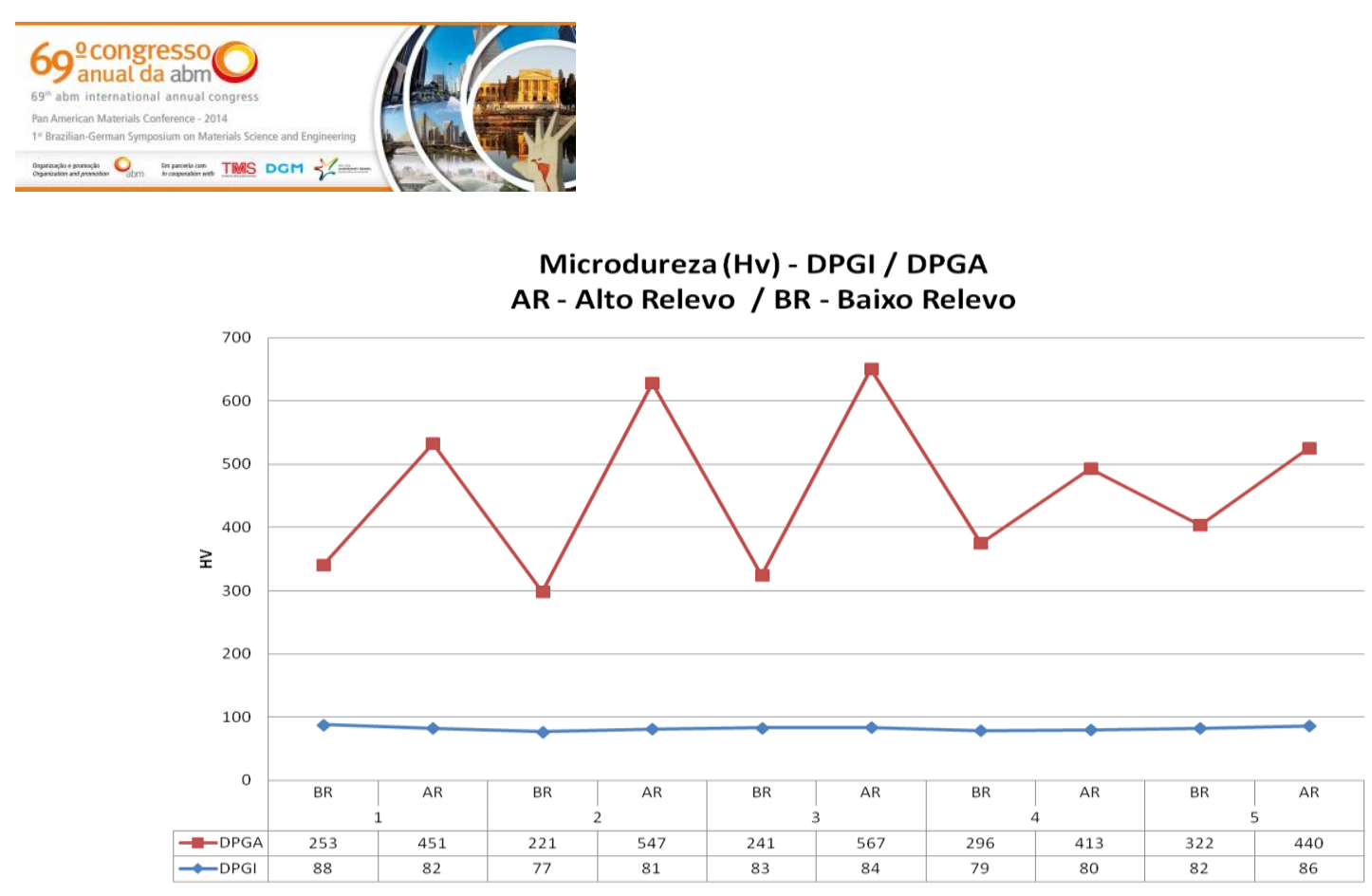

Fonte: ArcelorMittal Vega 2013

Figura 8 - Resultados de Microdureza para o DPGI e DPGA paras as áreas de alta (AR) e Baixa (BR) Relevo

Para caracterização tribológica do DPGI e DPGA foram realizados ensaios de coeficiente de atrito e a caracterização da evolução do revestimento ao longo da superfície de contato de $150 \mathrm{~mm}$ realizado pelo trajeto do tribômetro durante o ensaio.

Na Figura 9, é mostrado o comportamento tribológico do DPGI e DPGA quando submetidos ao aumento de pressão em tribômetro de matriz plana e sua correlação com as microestruturas obtidas por microscopia ótica. Para o DPGI verifica-se que de 0 a $3 \mathrm{MPa}$ não existe variação de coeficiente de atrito devido ao fechamento do ferramental e preparação para início do ensaio. À medida que ocorre o aumento da pressão de contato (entre 3 e $10 \mathrm{MPa}$ ) ocorre variações do coeficiente de atrito. Esta variação ocorre devido a utilização de sensor com força máximo igual a 1000 daN decanewton. ( $1 \mathrm{daN}=1,02 \mathrm{kgf}=10 \mathrm{~N})$, ou seja com baixas pressões. As baixas pressões normais as forças de tração podem variar entre 1 e 30 daN e o coeficiente de atrito entre 0,11 e 1,18. Com pressões de contato entre 10 e $45 \mathrm{MPa}$, é observado uma pequena variação, com um coeficiente de atrito médio de 0,133 . A partir de pressões de contato acima de $45 \mathrm{MPa}$ foi observado o fenômeno Stick Slip. No caso do coeficiente de atrito do DPGA observa-se as mesmas variações que para o DPGI (de 0 a $10 \mathrm{MPa}$ ), início de ensaio. Com pressões de contato entre $10 \mathrm{e}$ $37 \mathrm{MPa}$ observa-se aumento crescente dos valores de coeficiente de atrito com o aumento da pressão de contato. A partir da pressão de contato de $38 \mathrm{MPa}$ os valores o coeficiente de atrito tende a estabilizar permanecendo constante até o término do ensaio. Neste caso, o coeficiente de atrito médio foi de 0,155. Para o DPGA não foi observado o fenômeno Slip Stick.

Com relação à evolução da superfície galvanizada observa-se aumento das áreas deterioradas com o aumento da pressão de contato do tribômetro de ferramenta plana. O desgaste é mais evidente no DPGI onde o revestimento é composto basicamente de zinco puro. No DPGA ocorre também o desgaste, mas em menor nível se comparado ao DPGI em função das fases intermetálicas que compõem este revestimento.

\footnotetext{
* Contribuição técnica ao 69ำ Congresso Anual da ABM - Internacional e ao 14ํㅡㄹ ENEMET - Encontro Nacional de Estudantes de Engenharia Metalúrgica, de Materiais e de Minas, 21 a 25 de julho de 2014, São Paulo, SP, Brasil.
} 

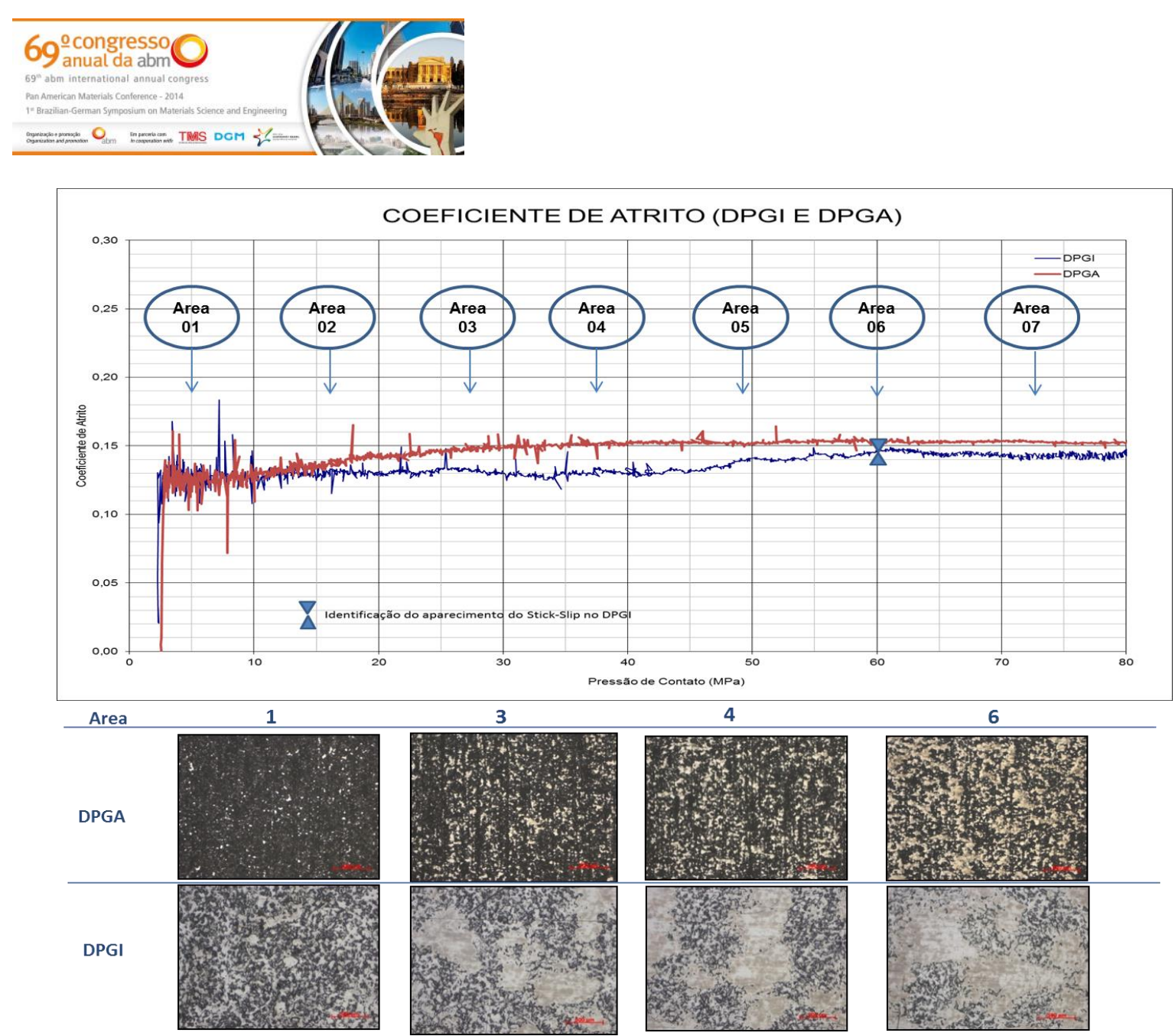

Figura 9 - Variação do comportamento de coeficiente de friç̧ão para o DP-GI (a) e DPGA (b) com o aumento da pressão de contato do prensa chapas e correlação com o aspecto superficial obtido por microscopia ótica. Fonte: ArcelorMittal Vega 2013

$\mathrm{Na}$ Figura 10 é possível verificar os resultados da evolução da Rugosidade e Densidade de Picos da superfície do revestimento ao longo do trajeto percorrido pelo tribômetro. Verificou-se que para o DPGI ocorreu redução, tanto da rugosidade quando de densidade de picos ao longo do trajeto do tribômetro sendo mais evidente a partir da área 3, ou seja, a partir de $28 \mathrm{MPa}$ de pressão de contato.

Para o DPGA, também se observou comportamento de redução nos valores de rugosidade e densidade de picos, porém em menor escala se comparado ao DPGI até a área $3(28 \mathrm{MPa})$. Porém, com pressões de contato maiores que $28 \mathrm{MPa}$ foi observado estabilidade nos resultados de rugosidade e densidade de picos.

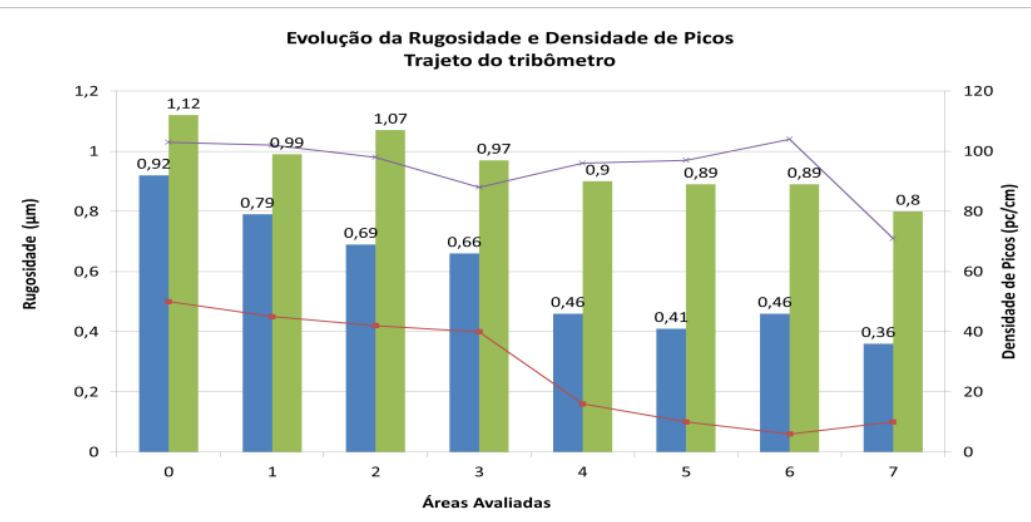

Figura 10 - Evolução da Rugosidade e Densidade de Picos da superfície do revestimento após ensaio de atrito. Fonte: ArcelorMittal Vega (2014)

* Contribuição técnica ao 69 Congresso Anual da ABM - Internacional e ao 14ํㅡㄹ ENEMET - Encontro Nacional de Estudantes de Engenharia Metalúrgica, de Materiais e de Minas, 21 a 25 de julho de 2014, São Paulo, SP, Brasil. 


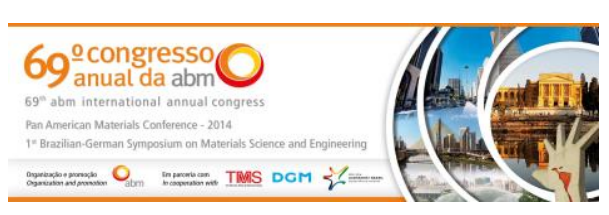

A Figura 11 mostra os resultados da relação entre a microdureza na região de contato do tribômetro e o coeficiente de atrito do DPGI e DPGA. Inicialmente, não são observadas variações de microdureza para o DPGI ao longo das áreas submetidas ao tribômetro, porém, ocorre à elevação do coeficiente de atrito com o aumento de pressão de contato do tribômetro. Apesar de não ser identificadas elevações na microdureza do DPGI, verifica-se incremento do coeficiente de fricção ocorrendo desgaste por abrasão, conforme verificado na Figura 9. O comportamento pode ser explicado pela microestrutura macia do revestimento composta basicamente de zinco-puro ou fase eta $(\eta)$.

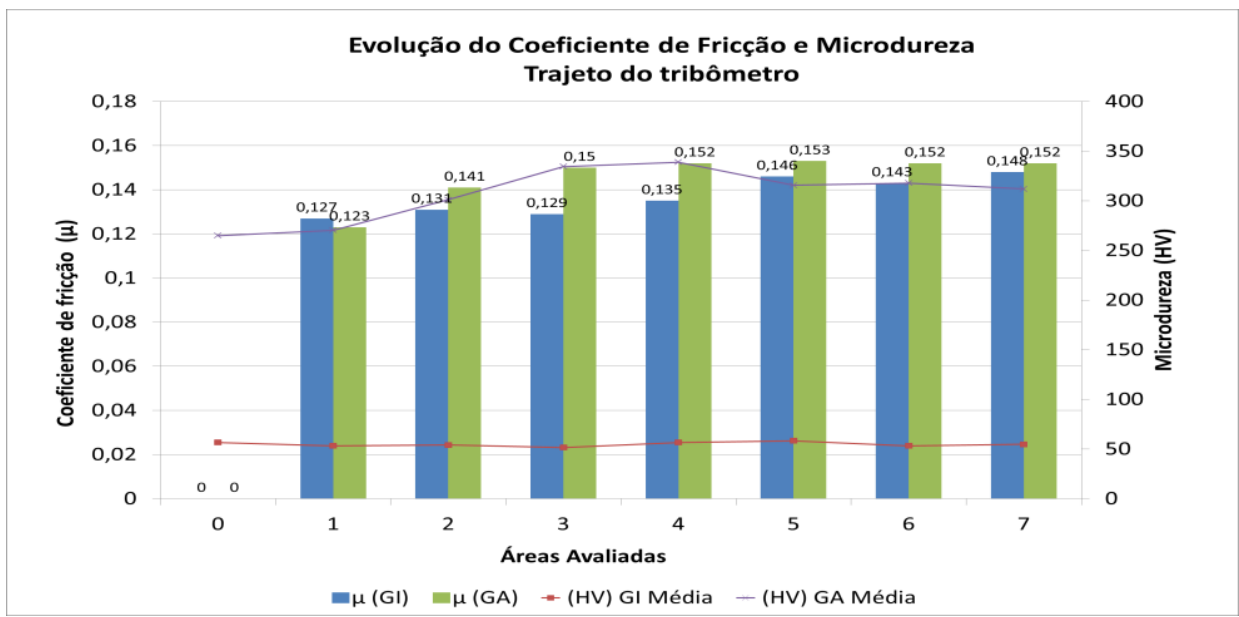

Figura 11 - Evolução da Microdureza do revestimento após ensaio de atrito. Fonte: ArcelorMittal Vega (2014)

No caso do DPGA, verifica-se o aumento dos valores de microdureza do revestimento, sendo observando estabilização dos valores a partir da área 4, ou seja, a partir de uma pressão de contato do tribômetro de $50 \mathrm{MPa}$. Neste caso observa-se menor desgaste visual se comparado ao DPGI. O fenômeno pode ser explicado primeiro pela característica do revestimento $\mathrm{Zn}-\mathrm{Fe}$ e das fases intermetálicas observadas na superfície deste revestimento. Neste caso, a fase

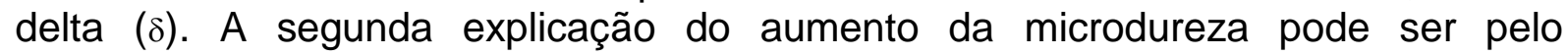
encruamento superficial do revestimento diante do aumento da pressão de contato do tribômetro.

\section{CONCLUSÃO}

- O estudo do comportamento tribológico do DPGI e DPGA utilizando um tribômetro de ferramenta plana, tornou possível medir o coeficiente de atrito e estimar a evolução do revestimento diante do aumento de pressão de contato. Estas informações podem auxiliar em projetos de confecção e a manutenção de matrizes e simulações numéricas de estampagem.

- Em virtude do método de produção utilizado para as tecnologias de galvanização e das características microestuturais dos revestimentos, observa-se comportamento tribológico diferente entre o DPGI e DPGA do ponto de vista de desgaste da superfície galvanizada, microdureza, rugosidade e densidade de picos.

- A utilização do laminador de encruamento na superfície galvanizada ocasionou um aumento significativo da microdureza do DPGA entre as áreas de baixo (BR) e alto relevo (AR). Não se observa a mesma evolução no DPGI.

\footnotetext{
* Contribuição técnica ao $69^{\circ}$ Congresso Anual da ABM - Internacional e ao 14ํㅡㄹ ENEMET - Encontro Nacional de Estudantes de Engenharia Metalúrgica, de Materiais e de Minas, 21 a 25 de julho de 2014, São Paulo, SP, Brasil.
} 


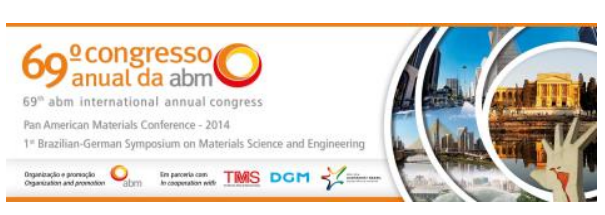

- No DPGI foi observado variação do coeficiente de atrito entre 0,11 a 0,18 diante da aplicação da pressão de contato de 3 a $80 \mathrm{MPa}$. O coeficiente médio de atrito medido até o aparecimento do Slip Stick foi de 0,132. O fenômeno Slip Stick foi observado a partir de 60MPa. No caso do DPGA, não foi observado o fenômeno de Slip Stick, sendo observada variação do coeficiente de atrito de 0,10 a 0,165. O coeficiente médio de atrito foi de 0,146 também medido entre 3 e $80 \mathrm{MPa}$.

- Foi observado que com o aumento da pressão de contado houve uma redução na rugosidade e densidade de picos. Para o DPGI, verifica-se redução da rugosidade de $0,92 \mu \mathrm{m}$ para $0,36 \mu \mathrm{m}$ e densidade de picos de 50 para $6 \mathrm{pc} / \mathrm{cm}$. No caso do DPGA, ocorre redução de rugosidade de $1,12 \mu \mathrm{m}$ para $0,80 \mu \mathrm{m}$ e densidade de picos de 103 para $71 \mathrm{pc} / \mathrm{cm}$.

- Com relação aos resultados de microdureza na região de contato do tribômetro e o coeficiente de atrito do DPGI, não foram observadas variações de microdureza. Porem, verifica-se elevação do coeficiente de atrito ocorrendo desgaste por abrasão a partir de $60 \mathrm{MPa}$. No caso do DPGA, verificou-se o aumento dos valores de microdureza do revestimento a partir de uma pressão de contato de $50 \mathrm{MPa}$. Neste caso, visualmente observou-se menor desgaste se comparado ao DPGI. O fenômeno pode ser explicado pela característica dos revestimentos (Zinco-Puro e $\mathrm{Zn}-\mathrm{Fe})$.

- Apesar das diferenças observadas entre o DPGI o DPGA, observa-se condições favoráveis para a utilização de ambos os materiais em processos de estampagem e pintura. Isso se dá em virtude da tecnologia dos processos de confecção de ferramentas de estampagem e linhas de pintura utilizadas atualmente.

\section{REFERÊNCIAS}

1 Lazik S, Esling C, Wegria J. Cracking in Zinc Layers on Continuous Galvanized Sheets A Review. Textures and microstructures, 1995; 23: 131-147.

2 Speich GR. Phisical Metallurgy of Dual Phase steels, United states steel corportarion, Monroeville, PA. 1981.

3 Bhattacharya D. Developments in Advanced High Strength Steels, Inner conference. Research and Development Center, Mittal Steel, East Chicago, Indiana, U.S.A, 2006

4 Kubaschewski OMT, Binary alloy phase diagrams. Metals Park, OH: ASM, p. 1128, 1986.

5 Marder AR. Microstructural Characterization of Zinc Coatings, Zinc Based Steel Coating Systems, 1990.

6 Kanamura T, Nakayama M. Alloying Reaction Control in Production of Galvannealed Steel. Materials science research international, 1995; 1(3): 150-156.

7 Mataigne JM. Key mechanisms in galvanization of steel sheets. Galvatech'07, p. 333338, 2007.

8 Matuszak A. Factors influencing friction in steel sheet forming. Journal of Materials Processing Tecnology, 2000; 106: 250-253.

9 Garza LG, Van Tyne CJ. Friction and formability of galvannealed interstitial free sheet steel. Journal of Materials Processing Technology, 2007; 187-188: 164-168.

\footnotetext{
* Contribuição técnica ao $69^{\circ}$ Congresso Anual da ABM - Internacional e ao 14ํㅡㄹ ENEMET - Encontro Nacional de Estudantes de Engenharia Metalúrgica, de Materiais e de Minas, 21 a 25 de julho de 2014, São Paulo, SP, Brasil.
} 